\title{
TRPM2-mediated $\mathrm{Ca}^{2+}$ influx induces chemokine production in monocytes that aggravates inflammatory neutrophil infiltration
}

\author{
Shinichiro Yamamoto ${ }^{1}$, Shunichi Shimizu ${ }^{2}$, Shigeki Kiyonaka ${ }^{1}$, Nobuaki Takahashi ${ }^{1}$, \\ Teruaki Wajima ${ }^{1}$, Yuji Hara ${ }^{1}$, Takaharu Negoro ${ }^{3}$, Toshihito Hiroi ${ }^{2}$, Yuji Kiuchi ${ }^{2}$, Takaharu \\ Okada $^{1}$, Shuji Kaneko ${ }^{4}$, Ingo Lange ${ }^{5}$ Andrea Fleig ${ }^{5}$, Reinhold Penner ${ }^{5}$, Miyuki Nishi ${ }^{6}$, \\ Hiroshi Takeshima ${ }^{6}$, and Yasuo Mori ${ }^{1}$ \\ ${ }^{1}$ Department of Synthetic Chemistry and Biological Chemistry, Graduate School of Engineering, \\ Kyoto University, Katsura Campus, Nishikyo-ku, Kyoto 615-8510, Japan. \\ ${ }^{2}$ Department of Pathophysiology, School of Pharmaceutical Sciences, Showa University, 1-5-8 \\ Hatanodai, Shinagawa-ku, Tokyo 142-8555, Japan. \\ ${ }^{3}$ Department of Medicinal Information, School of Pharmaceutical Sciences, Showa University, 1-5-8 \\ Hatanodai, Shinagawa-ku, Tokyo 142-8555, Japan. \\ ${ }^{4}$ Department of Molecular Pharmacology, Graduate School of Pharmaceutical Sciences, Kyoto \\ University, 46-29 Yoshida-Shimo-Adachi-cho, Sakyo-ku, Kyoto 606-8501, Japan. \\ ${ }^{5}$ Laboratory of Cell and Molecular Signaling, Center for Biomedical Research at The Queen's \\ Medical Center and John A. Burns School of Medicine at University of Hawaii, 1301 Punchbowl \\ Street, Honolulu, Hawaii 96813, USA. \\ ${ }^{6}$ Department of Biological Chemistry, Graduate School of Pharmaceutical Sciences, Kyoto \\ University, 46-29 Yoshida-Shimo-Adachi-cho, Sakyo-ku, Kyoto 606-8501, Japan.
}

\section{Abstract}

Reactive oxygen species (ROS) induce chemokines responsible for the recruitment of inflammatory cells to sites of injury or infection. Here we show that the plasma membrane $\mathrm{Ca}^{2+}$-permeable channel TRPM2 controls ROS-induced chemokine production in monocytes. In human U937 monocytes, hydrogen peroxide $\left(\mathrm{H}_{2} \mathrm{O}_{2}\right)$ evokes $\mathrm{Ca}^{2+}$ influx through TRPM2 to activate $\mathrm{Ca}^{2+}$-dependent tyrosine kinase Pyk2 and amplify Erk signaling via Ras GTPase. This elicits nuclear translocation of nuclear factor- $\mathrm{\kappa B}$ essential for the production of the chemokine interleukin-8 (CXCL8). In monocytes from Trpm2-deficient mice, $\mathrm{H}_{2} \mathrm{O}_{2}$-induced $\mathrm{Ca}^{2+}$ influx and production of the macrophage inflammatory protein-2 (CXCL2), the mouse CXCL8 functional homolog, were impaired. In the dextran sulfate sodium-induced colitis inflammation model, CXCL2 expression, neutrophil infiltration and ulceration were attenuated by Trpm 2 disruption. Thus, TRPM $2 \mathrm{Ca}^{2+}$ influx controls the ROS-induced signaling cascade responsible for chemokine production, which aggravates inflammation. We propose functional inhibition of TRPM2 channels as a new therapeutic strategy for treating inflammatory diseases.

\section{(C) 2008 Nature Publishing Group}

Correspondence should be addressed to Y.M. (mori@sbchem.kyoto-u.ac.jp)..

AUTHOR CONTRIBUTIONS S.Y., acquisition, analysis and interpretation of data and drafting of the manuscript; S.S., S. Kiyonaka, N.T., T.W., Y.H., T.N., T.H., T.O., I.L., A.F. and M.N., acquisition, analysis and interpretation of data; Y.K., S. Kaneko, R.P. and H.T., analysis and interpretation of data; Y.M., analysis and interpretation of data and drafting and critical review of the manuscript.

Note: Supplementary information is available on the Nature Medicine website.

Published online at http://www.nature.com/naturemedicine/

Reprints and permissions information is available online at http://npg.nature.com/reprintsandpermissions/ 
The biological purpose of inflammation is to bring fluids, proteins and inflammatory cells such as neutrophils and monocytes from the blood into the damaged tissues to eliminate the injuring agents and trigger the healing and repairing processes. Development of inflammatory reactions is controlled by a number of cellular and molecular components, including proinflammatory cytokines. Chemotactic cytokines, known as the chemokines, have a key role in mediating the recruitment of inflammatory cells to inflamed sites ${ }^{1}$. Among four subfamilies of chemokines ${ }^{1}$, CXC chemokines such as CXCL8 and its functional homolog CXCL2 (ref. ${ }^{2}$ ) are known to show potent neutrophil chemotactic activity.

At inflamed sites, neutrophils deploy a potent antimicrobial arsenal that includes proteinases, antimicrobial peptides and $\mathrm{ROS}^{3}$. Although ROS are extremely antimicrobial by virtue of their ability to kill microbial pathogens, in chronic inflammation, the continued production of ROS by neutrophils causes extensive tissue damage. Traditionally, this has been considered as random damage to cellular components ${ }^{4}$. Recently, ROS have emerged as signal transduction molecules ${ }^{5}$. In inflammatory cells, ROS contribute to the expression of a variety of different inflammatory cytokines, adhesion molecules and enzymes by activating redox-sensitive transcription factors such as nuclear factor- $\mathrm{\kappa B}(\mathrm{NF}-\kappa \mathrm{B})^{5}$.

Once monocytes adhere to endothelial cells from the bloodstream and migrate toward tissues, they differentiate into macrophages. During homeostasis, monocytes and macrophages phagocytose and remove senescent and apoptotic cells, whereas during inflammation they are the main effectors of innate immunity because of their antimicrobial activity and production of proinflammatory cytokines ${ }^{6}$. In human monocytes, CXCL8 production is induced by ROS, including by $\mathrm{H}_{2} \mathrm{O}_{2}$ (ref. ${ }^{7}$ ) via Erk-activated NF- $\mathrm{KB}$ (ref. ${ }^{8}$ ). It seems that increases in intracellular $\mathrm{Ca}^{2+}$ concentration $\left(\left[\mathrm{Ca}^{2+}\right]_{\mathrm{i}}\right)$ control the production of certain cytokines, including interleukin-2 (IL-2) in T cells ${ }^{9}$ and CXCL8 in monocytes ${ }^{10}$. The primary source for $\mathrm{Ca}^{2+}$ is probably extracellular, as reported in Mycobacterium bovis-induced CXCL8 production involving NF- $\mathrm{KB}$ (ref. ${ }^{11}$ ). Despite these noteworthy indications of the regulation of CXCL8 production by $\mathrm{ROS}$ and $\mathrm{Ca}^{2+}$ influx in monocytes, the molecular entities and signaling mechanisms that connect ROS, $\mathrm{Ca}^{2+}$ and chemokines are not clear.

$\mathrm{Ca}^{2+}$ influx is mediated through plasma membrane $\mathrm{Ca}^{2+}$-permeable cation channels. The Drosophila melanogaster transient receptor potential protein (TRP) and its homologs are polypeptide subunits that assemble into tetramers to form cation channels activated by sensing diverse stimuli from the extracellular environment and from inside the cell ${ }^{12}$. Mammalian TRPs comprise six subfamilies ${ }^{12}$. TRPM2, a member of the TRPM subfamily, is a $\mathrm{Ca}^{2+}$ permeable channel activated by intracellular messengers such as ADP-ribose (ADPR), nicotinamide adenine dinucleotide $\left(\mathrm{NAD}^{+}\right)$and cyclic ADPR (cADPR $)^{13-15}$. TRPM2 is abundantly expressed in inflammatory cells including monocytes, neutrophils and $\mathrm{T}$ lymphocytes ${ }^{13-15}$. We have reported that TRPM 2 acts also as a sensor for ROS and oxidative stress ${ }^{14}$. However, the exact mediator molecules for $\mathrm{H}_{2} \mathrm{O}_{2}$-induced TRPM2 channel activation remain to be identified. The ROS sensitivity of TRPM2 can be mediated by NAD ${ }^{+}$(ref. ${ }^{14}$ ) or ADPR ${ }^{15}$ released from mitochondria ${ }^{16}$ or through direct protein oxidation ${ }^{15} \cdot \mathrm{H}_{2} \mathrm{O}_{2}$ and cADPR have been proposed to potentiate the effects of ADPR at lower concentrations and to gate the TRPM2 channel directly at higher concentrations ${ }^{15}$. It has been suggested that $\mathrm{H}_{2} \mathrm{O}_{2}$-activated $\mathrm{Ca}^{2+}$ influx through TRPM2 mediates pathophysiological cell death ${ }^{14,17}$. However, with regard to normal physiological cellular responses, the importance of $\mathrm{H}_{2} \mathrm{O}_{2}$-activated $\mathrm{Ca}^{2+}$ influx remains to be elucidated. It is crucial that the key roles of the TRPM 2 channels be studied in the context of signaling mechanisms that control specific physiological responses.

Here we describe the functional role of TRPM2 in chemokine production. In U937 monocytes, $\mathrm{Ca}^{2+}$ influx via $\mathrm{H}_{2} \mathrm{O}_{2}$-activated TRPM2 mediates amplification of Erk activation and NF- $\mathrm{KB}$ nuclear translocation, which leads to CXCL8 production. In dextran sulfate sodium (DSS)- 
induced experimental colitis, which we employed as an inflammation model ${ }^{18}$ associated with $\operatorname{ROS}^{19,20}$, Trpm2-knockout mice showed attenuation of inflammatory indicators such as production of CXCL2, neutrophil infiltration and ulceration. Our study therefore suggests that ROS-evoked $\mathrm{Ca}^{2+}$ influx via TRPM2 represents a key inflammatory mediator in monocytes.

\section{RESULTS}

\section{$\mathrm{Ca}^{2+}$ influx via TRPM2 controls $\mathrm{H}_{2} \mathrm{O}_{2}$-induced CXCL8 expression}

In U937 cells, treatment with $\mathrm{H}_{2} \mathrm{O}_{2}$ induced mRNA expression and protein secretion of CXCL8 in a time- and dose-dependent manner (Supplementary Fig. 1a,b online). Consistent with previous reports $7,8,21,22$, CXCL8 production was suppressed by the Erk pathway inhibitor PD98059 and the NF-kB inhibitor PDTC (Fig. 1a,b and Supplementary Fig. 1c). By contrast, $\mathrm{H}_{2} \mathrm{O}_{2}$-induced CXCL8 production was unaffected by the immunosuppressive agent FK506, which inhibits expression of chemokines such as CCL23 via nuclear factor of activated T cells (NFAT) in monocytes (Supplementary Fig. 1d,e). These results show that the Erk and NF-kB pathways control $\mathrm{H}_{2} \mathrm{O}_{2}$-induced CXCL8 production in U937 cells.

$\mathrm{H}_{2} \mathrm{O}_{2}$-induced CXCL8 production in U937 cells was reduced by removal of extracellular $\mathrm{Ca}^{2+}$ (Fig. 1c), and robust $\mathrm{H}_{2} \mathrm{O}_{2}$-evoked $\left[\mathrm{Ca}^{2+}\right]_{\mathrm{i}}$ increases were observed only after readdition of $\mathrm{Ca}^{2+}$ to external solution (Fig. 1d), suggesting that $\mathrm{Ca}^{2+}$ influx is key in $\mathrm{H}_{2} \mathrm{O}_{2}$-induced CXCL8 production. On the basis of our previous observation that TRPM2 shows the highest sensitivity to $\mathrm{H}_{2} \mathrm{O}_{2}$ in mediating $\mathrm{Ca}^{2+}$ influx among TRP homologs ${ }^{14,23}$ and is abundantly expressed in monocytes ${ }^{13,14}$, we tested the effects of TRPM2-specific small interfering RNA (siRNA; Fig. 1e). As a result, $\mathrm{H}_{2} \mathrm{O}_{2}$-induced $\left[\mathrm{Ca}^{2+}\right]_{\mathrm{i}}$ increases and CXCL8 production were reduced in TRPM2-specific siRNA-treated U937 cells (Fig. 1f,g), clearly suggesting an involvement of native TRPM2 in the $\mathrm{Ca}^{2+}$ influx that controls the $\mathrm{H}_{2} \mathrm{O}_{2}$-induced CXCL8 production in human monocytes.

\section{TRPM2 mediates nuclear translocation of NF-KB}

We next investigated whether $\mathrm{Ca}^{2+}$ influx via TRPM2 and Erk contribute to activation of NF$\kappa B$. Nuclear translocation of the NF- $\kappa B$ subunit RelA was triggered within 30 min of $\mathrm{H}_{2} \mathrm{O}_{2}$ stimulation and reached a maximum after $60 \mathrm{~min}$ (Fig. 2a). This RelA translocation was attenuated by PD98059 (Fig. 2b), by removal of extracellular $\mathrm{Ca}^{2+}$ (Fig. 2c), which also suppressed the $\mathrm{H}_{2} \mathrm{O}_{2}$-induced DNA-binding activity of RelA (Supplementary Fig. 2a online), and by TRPM2-specific siRNA (Fig. 2d). The phosphorylation and subsequent degradation of inhibitor of $\kappa \mathrm{B}(\mathrm{I} \kappa \mathrm{B})$ and Erk-mediated phosphorylation of IкB kinase- $\beta$ (IKK- $\beta$ ), responsible for RelA nuclear translocation, were also suppressed by removal of extracellular $\mathrm{Ca}^{2+}$ (Fig. $2 \mathrm{e}-\mathrm{h})$. By contrast, transcription levels of signaling components of the canonical NF- $\mathrm{kB}$ pathway (Supplementary Fig. 2b) and protein expression levels of IKK- $\beta$ (Fig. 2g,h) were unaffected by $\mathrm{H}_{2} \mathrm{O}_{2}$ administration or by coapplication of PD98059. Furthermore, phosphorylation of IкB kinase- $\alpha$ (IKK- $\alpha$; Fig. $2 \mathrm{~g}, \mathrm{~h}$ ) and processing of protein p100 into p52 and its nuclear translocation (Supplementary Fig. 2c,d), which is essential for the noncanonical NF- $\kappa B$ pathway ${ }^{24}$, were insensitive to $\mathrm{H}_{2} \mathrm{O}_{2}$ and $\mathrm{Ca}^{2+}$ removal. Thus, $\mathrm{H}_{2} \mathrm{O}_{2}$-induced activation of the canonical NF- $\mathrm{kB}$ pathway is positively regulated by Erk and TRPM2-mediated $\mathrm{Ca}^{2+}$ influx in monocytes.

\section{TRPM2 amplifies Erk signal via Pyk2 and Ras activation}

Erk activation was induced by $\mathrm{H}_{2} \mathrm{O}_{2}$ within 2-5 min for Erk1 and 1 min for Erk2, reaching maximum levels after 10-20 min (Fig. 3a). After removal of extracellular $\mathrm{Ca}^{2+}$, however, the activation of Erk1 was markedly reduced, although the Erk2 response to $\mathrm{H}_{2} \mathrm{O}_{2}$ was relatively intact (Fig. 3a). These results suggest that $\mathrm{Ca}^{2+}$ influx has a major role in Erk activation, reflected by the sustained phosphorylation of mainly Erk1 after 10-20 min of $\mathrm{H}_{2} \mathrm{O}_{2}$ stimulation 
(Fig. 3a). Much of this $\mathrm{Ca}^{2+}$ influx is probably mediated by TRPM2 channels, as $\mathrm{H}_{2} \mathrm{O}_{2}$-induced Erk1 activation was reduced by TRPM2-specific siRNA (Fig. 3b).

Ras, which represents an upstream signaling molecule of Erk, was gradually activated by $\mathrm{H}_{2} \mathrm{O}_{2}$, and its activation reached a plateau within $5 \mathrm{~min}$, whereas this activation was abolished by removal of extracellular $\mathrm{Ca}^{2+}$ in U937 cells (Fig. 3c). A further upstream signaling molecule, the $\mathrm{Ca}^{2+}$-sensitive, proline-rich tyrosine kinase Pyk2, is known to activate the Ras-Erk pathway ${ }^{25}$. Notably, a kinase-negative Pyk2 mutant (Pyk2-DN) that acts as a dominant negative ${ }^{25}$ suppressed $\mathrm{H}_{2} \mathrm{O}_{2}$-evoked Ras and Erk activation (Fig. $3 d$ ). Erk activation was also suppressed by Pyk2-specific siRNAs (Fig. 3e), which suppressed nuclear translocation of NF$\kappa \mathrm{B}$ as well (Fig. 3f). Furthermore, the Pyk2 activation observed within 5 min of $\mathrm{H}_{2} \mathrm{O}_{2}$ stimulation was abolished by removal of extracellular $\mathrm{Ca}^{2+}(\mathrm{Fig} .3 \mathrm{~g})$ and was attenuated by TRPM2-specific siRNA (Fig. 3h and Supplementary Fig. 2e). However, siRNAs for two other candidate signaling molecules responsible for coupling of $\mathrm{Ca}^{2+}$ influx to Ras activation, RasGRP2 and RasGRP4, expressed in U937 cells ${ }^{26}$ failed to inhibit $\mathrm{H}_{2} \mathrm{O}_{2}$-induced Erk activation (Supplementary Fig. 2f). We also examined two mitogen-activated protein kinases (MAPKs), JNK and p38-MAPK, activated by $\mathrm{H}_{2} \mathrm{O}_{2}$ with different time courses

(Supplementary Fig. 2g-j). After removal of extracellular $\mathrm{Ca}^{2+}$, JNK showed a slight delay but an intact maximal level of $\mathrm{H}_{2} \mathrm{O}_{2}$-induced activation, whereas p38-MAPK was essentially unaffected (Supplementary Fig. 2g,h). The p38-MAPK inhibitor SB203580 nearly abolished but the JNK inhibitor SP600125 failed to suppress $\mathrm{H}_{2} \mathrm{O}_{2}$-induced CXCL8 expression (Supplementary Fig. 2i,j). These data suggest that p38-MAPK contributes to $\mathrm{H}_{2} \mathrm{O}_{2}$-evoked CXCL8 expression independently of $\mathrm{Ca}^{2+}$ influx. Thus, $\mathrm{Ca}^{2+}$ influx via $\mathrm{H}_{2} \mathrm{O}_{2}$-activated TRPM2 triggers Pyk2 and Ras activation, which then amplifies Erk activation, leading to nuclear translocation of NF-אB and CXCL8 production in U937 monocytes.

\section{Trpm2 knockout disrupts chemokine production in monocytes}

To study the physiological importance of TRPM2 channels and their in vivo effects on the signal transduction pathway revealed above, we generated transgenic mice in which TRPM2 expression was knocked out (Supplementary Fig. 3a-c online). Trpm2-knockout mice were viable, fertile and largely indistinguishable from wild-type (WT) littermates in general appearance, body weight, locomotion and overt behavior. Of note, a TRPM2 immunoreactivity that localized near the plasma membrane in monocytes from WT mice was absent in monocytes isolated from Trpm2-knockout mice (Fig. 4a). In monocytes obtained from WT mice, intracellular perfusion with increasing concentrations of ADPR evoked cationic currents (Fig. 4b). Monocytes isolated from Trpm2-knockout mice failed to respond entirely, and no substantial changes in current were ever observed (Fig. 4c,d). Similarly, WT monocytes typically responded to $\mathrm{H}_{2} \mathrm{O}_{2}$ by robust increases in cationic current $(\mathrm{Fig} .4 \mathrm{e}, \mathrm{f})$ and $\left[\mathrm{Ca}^{2+}\right]_{\mathrm{i}}(\mathrm{Fig}$. $4 \mathrm{~g}$ ), whereas these phenotypes were nearly abolished in Trpm2-knockout monocytes (Fig. 4eg). The $\left[\mathrm{Ca}^{2+}\right]_{\mathrm{i}}$ response defect was restored by cDNA transfection of TRPM2 but not by transfection of a cDNA encoding a TRPM2 mutant lacking the MutT motif essential for the action of the activators (Supplementary Fig. 3d) ${ }^{13,14}$. With regard to other types of cationic currents, $\mathrm{Mg}^{2+}$ - and ATP-regulated TRPM7-like current as well as $\mathrm{Ca}^{2+}$-release activated $\mathrm{Ca}^{2+}$ current and $\mathrm{Ca}^{2+}$ influx evoked by store depletion were intact in Trpm2-knockout monocytes (Supplementary Fig. 3e-g).

As reported for the mouse macrophage cell line B10R (ref. ${ }^{27}$ ), exposure of monocytes to 25 $\mu \mathrm{M} \mathrm{H}_{2} \mathrm{O}_{2}$ induced expression of CXCL2 in WT cells, whereas this was impaired in mutant monocytes (Fig. 5a). CXCL2 expression induced by the endotoxin lipopolysaccharide and tumor necrosis factor- $\alpha$, known as physiological stimulators of the ROS pathway ${ }^{28}$, was also suppressed in Trpm2-knockout monocytes (Supplementary Fig. 4a online). In contrast, knockout of Trpm2 did not affect expression of other cytokines sensitive (IL-1 $\beta$, CCL2, CCL3, 
CCL4 and CXCL12) and insensitive (CCL1 and CCL21) to $\mathrm{H}_{2} \mathrm{O}_{2}$ induction in mouse monocytes (Supplementary Fig. 4b). With regard to $\mathrm{H}_{2} \mathrm{O}_{2}$-induced activation, Pyk2, Erk and IKK (Fig. 5b), but not the noncanonical NF- $\kappa$ B pathway, p38-MAPK and JNK (Supplementary Fig. 4c-e), were impaired in Trpm2-knockout monocytes. These data, together with suppression of $\mathrm{H}_{2} \mathrm{O}_{2}$-induced CXCL2 expression by the Erk and NF- $\mathrm{kB}$ inhibitors (Fig. 5c), strongly suggest that the $\mathrm{H}_{2} \mathrm{O}_{2}$-induced signaling cascade proposed for CXCL8 in U937 cells is applicable to CXCL2 in mouse monocytes ${ }^{29}$. The crucial contribution of NF- $\mathrm{KB}$ to RNA expression of CXCL2 has been also reported previously in comparison with other chemokines ${ }^{27}$.

In vitro neutrophil migration toward the conditioned medium collected from WT monocyte cultures was significantly $(P<0.01)$ increased by $\mathrm{H}_{2} \mathrm{O}_{2}$ pretreatment, whereas this effect of $\mathrm{H}_{2} \mathrm{O}_{2}$ was nearly abolished when medium from Trpm2-knockout monocytes was used (Fig. 5d) or when neutralizing monoclonal antibody to CXCL2 was added to the WT medium (Fig. 5e). Thus, the differences of $\mathrm{H}_{2} \mathrm{O}_{2}$-induced CXCL2 expression observed in WT and Trpm2knockout monocytes can influence the chemoattractant properties of monocytes and affect neutrophil migration. Notably, however, we did not observe statistically significant differences in CXCL2-induced $\mathrm{Ca}^{2+}$ responses and in vitro migration between WT and Trpm2-knockout neutrophils (Supplementary Fig. 5a,b online), suggesting that CXCL2-induced responses in neutrophils are not dependent on TRPM2 activation. This is in contrast to $\mathrm{Ca}^{2+}$ responses and migration induced by a potent granulocyte chemoattractant, formyl-methionylleucyl-

phenylalanine (fMLP) (Supplementary Fig. 5c,d).

\section{Ulcerative colitis is suppressed in Trpm2-knockout mice}

To establish the physiological significance in vivo of TRPM2-mediated CXCL2 production in ROS-stimulated monocytes, we examined the DSS model, in which mice show acute colitis characterized by epithelial injury and an acute inflammatory infiltrate ${ }^{18}$ and many symptoms similar to those seen in human ulcerative colitis, that is, diarrhea, bloody feces, body weight loss, mucosal ulceration and shortening of colon ${ }^{18,19}$. In the DSS model, enhanced ROS release ${ }^{19,20}$ and CXCL2 secretion have been reported to exacerbate ulcerative colitis ${ }^{30}$. As expected, expression of CXCL2 was greatly increased both in monocytes and in colon of DSStreated WT mice, whereas CXCL2 expression was strongly suppressed in DSS-treated Trpm2-knockout mice (Fig. 6a,b). The proinflammatory cytokines interferon- $\gamma($ IFN- $\gamma$ ) and IL-12 (a potent IFN- $\gamma$ inducer released from macrophages) were also significantly $(P<0.01)$ suppressed (Supplementary Fig. 6 online). In contrast, knockout of Trpm 2 did not diminish expression in the colon of IL-6, IL-10, CCL1, CCL2, CCL3 and CCL5 (Supplementary Fig. 6a-c); the phenotypes of in vitro migration induced by CCL1, CCL2, CCL3, and CCL5 were intact in neutrophils and monocytes (Supplementary Fig. 5e,f). Notably, the number of recruited GR1-positive neutrophils was markedly reduced in DSS-treated Trpm2-knockout mice, whereas the number of macrophages $\left(\mathrm{F} 4 / 80^{+}\right.$or $\mathrm{CD} 11 \mathrm{~b}^{+} \mathrm{Ly} 6 \mathrm{C}^{\text {high }} \mathrm{Ly} 6 \mathrm{G}^{\mathrm{low}}$ cells) after infiltration into tissues was indistinguishable between WT and Trpm2-knockout mice (Fig. $6 \mathrm{c}, \mathrm{d}$ and Supplementary Fig. 6d,e). Myeloperoxidase activity, an indicator of neutrophil infiltration after induction of colitis, was also reduced in DSS-treated Trpm2-knockout colon (Fig. 6e). This defect was restored by transfer of WT macrophages and TRPM2- or CXCL2specific cDNA-transfected Trpm2-knockout macrophages derived from the bone marrow (Supplementary Fig. 7 online).

It is noteworthy that Trpm2-knockout neutrophils retained in vivo neutrophil functions, which include infiltration of neutrophils introduced by bone marrow cell transfer into the DSS-treated colon (the ratio of infiltrated WT over Trpm2-knockout neutrophils was $0.96 \pm 0.11(n=5)$; Supplementary Fig. 8a,b online) and bone marrow output and infiltration of neutrophils into the abdominal cavity after intraperitoneal injection of CXCL2 (Supplementary Fig. 8c). In 
vivo neutrophil output and infiltration elicited by intraperitoneal injection of CCL1, CCL3 and CCL5 was also intact in mutant mice, whereas that induced by fMLP was impaired in accordance with the in vitro migration data (Supplementary Figs. 5d and 8d-g). Trpm2knockout neutrophils showed partially impaired, yet significant $(P<0.05)$, bone marrow output in the DSS model (Supplementary Fig. 8h), which is consistent with the idea that bone marrow output is controlled by the balance between the chemoattractants released from the colon and those within the bone marrow. With regard to other immunocytes, $\mathrm{T}$ cells, dendritic cells and NK cells, DSS-induced infiltration was intact in Trpm2-knockout colon (Supplementary Fig. 6f). When introduced by bone marrow transfer, these immunocytes also showed intact colon infiltration (Supplementary Fig. 8b). These in vivo data, in combination with the intact in vitro migration of Trpm2-knockout neutrophils toward CXCL2 (Supplementary Fig. 5b), suggest that diminished expression of CXCL2 in macrophages contributes to the paucity of neutrophil accumulation in the colons of DSS-treated Trpm2-knockout mice.

Clinical assessments of disease activity showed profound inflammation and tissue destruction in the colon, characterized by mucosal ulceration, serosa destruction and infiltration of inflammatory cells in WT mice, whereas in Trpm2-knockout mice, the severity of the DSSinduced colitis was substantially reduced, although epithelial injury was identified (Fig. 6f,g). Moreover, Trpm2-knockout mice did not show DSS-induced loss of body weight and shortening of colon (Supplementary Fig. 6g,h). Thus, Trpm2-knockout mice were largely protected from DSS-mediated colitis, suggesting that TRPM2 has major roles in the progressive severity of inflammation.

\section{DISCUSSION}

The results of the present study show a key role of the $\mathrm{Ca}^{2+}$-permeable channel TRPM2 in $\mathrm{H}_{2} \mathrm{O}_{2}$-induced chemokine production in monocytes that is of major physiological consequence in inflammation. Our in vitro studies in the human monocytotic cell line U937 suggest that $\mathrm{H}_{2} \mathrm{O}_{2}$ activates TRPM2 and amplifies downstream Ras and Erk signaling via Pyk2, leading to nuclear translocation of NF- $\mathrm{KB}$ and production of CXCL8. Our in vivo studies in Trpm2knockout mice show that TRPM2 controls CXCL2 production in monocytes, which induces neutrophil migration and exacerbates DSS-induced ulcerative colitis.

It has been shown that Ras augments $\mathrm{H}_{2} \mathrm{O}_{2}$-induced CXCL8 production in experiments knocking down hypoxia inducible factor-1 (HIF-1), the transcription factor that controls scavenging of ROS in hypoxic conditions ${ }^{22}$. Of note, hypoxia-induced CXCL8 production via NF- $\mathrm{KB}$ activation is observed in HIF-1-deficient colon cancer DLD-1, which harbors an oncogenic KRAS mutation, but not in HIF-1-deficient colon cancer Caco2 cells carrying WT $K R A S$. This suggests that sustained activation of KRAS is crucial for $\mathrm{H}_{2} \mathrm{O}_{2}$-mediated CXCL8 production in colon cancer, which is consistent with the amplified Ras signal we observed for CXCL8 production in monocytes. With regard to other MAP kinases, the contribution of p38MAPK to $\mathrm{H}_{2} \mathrm{O}_{2}$-induced CXCL8 expression is crucial but is independent of the TRPM2mediated cascade, whereas the contribution of JNK is minimal, if any. This is consistent with the previously reported involvement of p38-MAPK in post-transcriptional regulation of CXCL8 expression ${ }^{31}$.

NF- $\kappa \mathrm{B}$ seems to be fully responsible for the $\mathrm{H}_{2} \mathrm{O}_{2}$-induced CXCL8 production in U937 cells (Fig. 1b), but $\mathrm{H}_{2} \mathrm{O}_{2}$-induced NF- $\mathrm{KB}$ nuclear translocation and CXCL8 production are partially TRPM2 and Mek independent (PD98059-insensitive) (Figs. 1a,c,g and 2b-d and Supplementary Fig. 1b). A possible mechanism regarding Erk activation that could account for this observation might be a decrease in phosphatase activity, as protein tyrosine phosphatases (PTPs) can be inhibited by $\mathrm{H}_{2} \mathrm{O}_{2}$ (ref. ${ }^{32}$ ). Specifically, inhibition of hematopoietic PTP (HePTP) expressed in U937 cells ${ }^{33}$ might be involved, as HePTP inhibition 
has been reported to trigger Erk activation without Mek activation ${ }^{32}$. In addition, PTP inhibition positively regulates $\mathrm{H}_{2} \mathrm{O}_{2}$-evoked TRPM2 activation ${ }^{34}$. Therefore, some Erk activation through HePTP inhibition may be responsible for the residual nuclear trans-location of NF$\kappa \mathrm{B}$ and CXCL8 production independent of TRPM2 and Mek. Notably, compared to Erk, the upstream Pyk2 showed more transient activation. This may be a result of $\mathrm{H}_{2} \mathrm{O}_{2}$-resistant PTPs that dephosphorylate and inactivate Pyk2.

At inflamed sites ${ }^{4}$, multiple cells including neutrophils, macrophages and epithelial cells express NADPH oxidase, which generates $\operatorname{ROS}^{3,4,35}$. Cumulative evidence supports that ROS may function as mediators for aggravation of symptoms and pathophysiological responses in ulcerative colitis ${ }^{19,20}$. In mice, deficiency of nuclear factor erythroid-2-related factor-2 (Nrf2), a redox-sensitive transcriptional factor that regulates antioxidant genes ${ }^{36}$, or an impaired superoxide dismutase activity ${ }^{18}$ has been reported to increase susceptibility to DSS-induced colitis, indicating a major role of antioxidants in protecting the intestine against ROS in colitis. Notably, $100 \mu \mathrm{M} \mathrm{H}_{2} \mathrm{O}_{2}$ induced cell death in only $20 \%$ of U937 cells ${ }^{14}$ but induced submaximal activation of CXCL8 transcription (nearly 80\% maximum; Supplementary Fig. 1b). Hence, we hypothesize that moderate ROS exposure is a key signal for chemokine production and initiation of healing, whereas excessive ROS production and persistent $\mathrm{Ca}^{2+}$ entry may tilt the balance toward severe tissue damage and cell death.

CXCL2, similar to CXCL8 in humans, is one of the major inducible chemokines that lead to neutrophil infiltration ${ }^{2}$ and subsequent tissue injury in several animal models of inflammation and injury, including ulcerative colitis ${ }^{30,37,38}$. Our results obtained from Trpm2-knockout mice fit well into this context, as mutant monocytes show impaired $\mathrm{H}_{2} \mathrm{O}_{2}$-induced expression of CXCL2. In contrast to CXCL2, keratinocyte-derived chemokine CXCL1, which also causes neutrophil chemotaxis ${ }^{2}$, CCL19 and CXCL13 were undetectable in these cells (data not shown), and other cytokines tested were not susceptible to $\mathrm{H}_{2} \mathrm{O}_{2}$-inducted expression in mouse monocytes or showed intact $\mathrm{H}_{2} \mathrm{O}_{2}$-inducible expression in Trpm2-deficient monocytes. Therefore, the impaired in vitro neutrophil migration induced by conditioned medium containing chemokines from $\mathrm{H}_{2} \mathrm{O}_{2}$-treated Trpm2-knockout monocytes is probably attributable to reduced $\mathrm{H}_{2} \mathrm{O}_{2}$-induced CXCL2 expression. In monocytes and colon from DSStreated Trpm2-knockout mice, CXCL2 expression is suppressed, whereas expression of IL-6, IL-10, CCL1, CCL2, CCL3 and CCL5 showed intact DSS inducibility. Inflammation parameters such as neutrophil infiltration and ulceration in the colon were also reduced in DSStreated Trpm2-knockout mice. However, we did not observe statistically significant differences in DSS-induced macrophage recruitment between WT and Trpm2-knockout colons. Notably, Trpm2 deficiency did not impair key aspects of CXCL2-evoked neutrophil chemotaxis, including $\mathrm{Ca}^{2+}$ response, in vitro migration, in vivo infiltration after bone marrow transfer or in response to intraperitoneal CXCL2 injection, and bone marrow output. Recruitment of T cells, NK cells and dendritic cells also seemed intact in Trpm2-knockout colon. These results suggest that, overall, TRPM2 in macrophages accounts for much of the exacerbation of DSSinduced ulcerative colitis by mediating $\mathrm{H}_{2} \mathrm{O}_{2}$-triggered CXCL2 production and neutrophil infiltration. Nevertheless, it remains to be examined whether the Trpm 2 defect exerts effects widely on hematopoietic or nonhematopoietic cells, including epithelial cells, or on responses mediated by factors other than $\mathrm{H}_{2} \mathrm{O}_{2}$. Inthis context, it is noteworthy that DSS-induced expression of proinflammatory cytokines IFN- $\gamma$ and IL- 12 was diminished in the Trpm2deficient colon, as these phenotypic changes that relieve tissue damage and inflammation are indicative of functional defects of monocyte-derived cells. Furthermore, neutrophilic $\mathrm{Ca}^{2+}$ responses and in vitro migration induced by fMLP and monocytotic CXCL2 expression induced by proinflammatory endotoxin lipopolysaccharide and cytokine tumor necrosis factor$\alpha$ showed sensitivity but also some resistance to impairment by Trpm 2 knockout. Thus, future studies need to address relationships between multiple TRPM2-dependent and TRPM2independent pathways in the complex in vivo DSS model and in human inflammatory diseases. 
The tissue damage in human ulcerative colitis is probably mediated by neutrophils that have infiltrated the colonic mucosa, with CXCL8 representing the most potent specific neutrophil chemoattractant ${ }^{39}$. The degree of elevation of CXCL8 abundance is correlated with both disease activity and sigmoidoscopic severity in the dialysate bags ${ }^{39}$ and with increased levels of infiltration of neutrophils in ulcerative colitis mucosa ${ }^{40}$. Notably, chronic inflammatory bowel diseases are mediated by activated monocytes and macrophages ${ }^{41,42}$, whereas induction of CXCL8 expression is induced in the lamina propria macrophages of ulcerative colitis mucosa ${ }^{43}$. Kupffer cells, the resident liver macrophages, produce and release various proinflammatory cytokines, including CXCL8, leading to exacerbation of inflammatory liver disease ${ }^{44}$, and CXCL8 produced by alveolar macrophages is involved in the development of chronic obstructive pulmonary disease ${ }^{45}$. By contrast, in vivo epithelial expression of CXCL8 is absent or minimal, although an in vitro capacity of epithelial cells to release CXCL8 has been demonstrated ${ }^{43}$. These studies, in combination with our Trpm2-knockout mouse studies, suggest a key role of CXCL8 produced by TRPM2 in monocytes and macrophages in the exacerbation of human ulcerative colitis. Of note, genetic links between TRPM2 and defective inflammatory diseases such as amyotrophic lateral suclerosis and parkinsonism dementia have been suggested ${ }^{46}$. Therefore, it is conceivable that CXCL8 production via TRPM2 triggers various inflammatory responses. This raises the prospect that suppression of CXCL8 production by inhibition of TRPM 2 might be an effective way to reduce pathological severity in ulcerative colitis and many other inflammatory diseases related to ROS production.

ADPR may be a major messenger molecule that links ROS to TRPM2 activation and $\mathrm{Ca}^{2+}$ entry in inflammation, because excessive oxidative stress leads to enzymatic ADPR production in inflammatory chemokine production ${ }^{47-49}$ and ADPR mobilization from mitochondria ${ }^{16}$. In immunocytes, including neutrophils, CD38 produces cADPR and ADPR ${ }^{50}$. CD38-deficient neutrophils have disturbed $\mathrm{Ca}^{2+}$ signaling and chemotaxis in response to fMLP via fMLP receptors ${ }^{50}$. Notably, the fMLP-induced $\mathrm{Ca}^{2+}$ response and in vitro migration were suppressed in Trpm2-deficient neutrophils. This supports the idea that fMLP activates CD38 to induce cADPR and ADPR production and the $\mathrm{Ca}^{2+}$ influx via TRPM2 required for neutrophil chemotaxis ${ }^{15}$, in contrast to the CXCL2-induced neutrophil chemotaxis that does not receive a significant contribution from TRPM 2 channels and that is probably mediated by classical inositol triphosphate-induced $\mathrm{Ca}^{2+}$ release and possibly store-operated $\mathrm{Ca}^{2+}$ entry. It will be useful to study which type of signaling mechanism other chemokines employ in inducing chemotaxis.

\section{METHODS}

\section{Isolation of mouse monocytes}

We isolated monocytes from peripheral blood mononuclear cells by CD11b positivity using a magnetic sorting system. All animal experiments were performed in accordance with protocols approved by the Institutional Animal Care and Use Committees of the Graduate School of Engineering, Kyoto University. For details, see Supplementary Methods online.

\section{Northern blot analysis}

We carried out hybridization with cDNA probes for TRPM2, CXCL8 or 18S rRNA. For details, see Supplementary Methods.

\section{Determination of human CXCL8 and mouse CXCL2 concentration}

We determined concentrations of human CXCL8 from U937 cells and CXCL2 from mouse monocytes or colons by ELISA according to the manufacturers' instructions (Endogen and R\&D Systems, respectively). 


\section{Small interfering RNA}

We used the TRPM2 siRNA sequence targeting the coding region of TRPM2 mRNA (5'AAAGCCTCAGTTCGTGGATTC-3') and the Pyk2 siRNA sequences targeting the coding region of Pyk2 mRNA (5'-AATGCACTTGACAAGAAGTCC-3'), (5'-

AAGATGTGGTCCTGAATCGTA-3'), (5'-AAGGTGTCTACACAAATCACA- $\left.3^{\prime}\right)$, and (5'AAGTCCCTGGACCCCAT GGTT-3'). We used cells $48 \mathrm{~h}$ after siRNA transfection. We used an siRNA directed against glyceraldehyde-3-phosphate dehydrogenase (GAPDH) as a control. For details, see Supplementary Methods.

\section{Measurement of changes in intracellular calcium concentration}

We measured changes in $\left[\mathrm{Ca}^{2+}\right]_{\mathrm{i}}$ as previously described ${ }^{23}$. We measured the fura- 2 fluorescence in HEPES-buffered saline containing (in mM): $107 \mathrm{NaCl}, 6 \mathrm{KCl}, 1.2 \mathrm{MgSO}_{4}, 2$ $\mathrm{CaCl}_{2}, 11.5$ glucose and 20 HEPES (pH 7.4, adjusted with $\mathrm{NaOH}$ ). We obtained the 340:380 $\mathrm{nm}$ ratio images on a pixel-by-pixel basis.

\section{Nuclear translocation of nuclear factor-kB}

We determined nuclear translocation of NF-KB by western blotting. We detected the total amount of $\beta$-actin as the loading control. For details, see Supplementary Methods.

\section{Western blot analysis}

We determined activation of Erk, Pyk2, IкB, IKK- $\beta$, IKK- $\alpha$ and degradation of I $\mathrm{B}$ by western blotting. For details, see Supplementary Methods.

\section{Ras-GTP assay}

We prebound bacterially expressed GST-Ras binding domain (amino acids 1-149 of human cRaf-1 fused to GST) to glutathione-conjugated beads and incubated the beads with each cell lysate. We subjected bound proteins to western blotting. For details, see Supplementary Methods.

\section{Pyk2 activation assay}

We immunoprecipitated cell lysates for $2 \mathrm{~h}$ at $4{ }^{\circ} \mathrm{C}$ with protein A-agarose linked to Pyk2specific antibody (Upstate). We analyzed immunoprecipitates by western blotting with phosphotyrosine-specific antibody (Upstate). Details of the procedure for immunoprecipitation are described in Supplementary Methods.

\section{Confocal immunovisualization in isolated monocytes}

We fixed monocytes with paraformaldehyde, immunostained them with TRPM2-specific antibody (1:100 mLTRPC2-C1; ref. $\left.{ }^{14}\right)$ and visualized them with the Alexa Fluor 488conjugated rabbit IgG-specific antibody (Invitrogen) to detect TRPM2. We acquired the fluorescence images with a confocal laser-scanning microscope (Olympus FV500) using the 488-nm line of an argon laser for excitation and a 505-nm long-pass filter for emission.

\section{Electrophysiology}

We performed patch-clamp experiments in the whole-cell configuration. We kept cells in standard Ringer's solution (in $\mathrm{mM}$ ): $140 \mathrm{NaCl}, 2.8 \mathrm{KCl}, 1 \mathrm{CaCl}_{2}, 2 \mathrm{MgCl}_{2}, 10$ glucose and 10 HEPES-NaOH (pH 7.2 adjusted with $\mathrm{NaOH}$ ). Standard pipette-filling solutions contained (in $\mathrm{mM}$ ): 140 Cs-glutamate, $8 \mathrm{NaCl}, 1 \mathrm{MgCl}_{2}$ and 10 HEPES-CsOH (pH 7.2 adjusted with $\mathrm{CsOH}$ ). We left $\mathrm{Ca}^{2+}$ unbuffered by leaving out any calcium chelator. We acquired all data with Pulse software controlling an EPC-9 amplifier (HEKA) and analyzed with FitMaster (HEKA) and Igor Pro (Wavemetrics). For details, see Supplementary Methods. 


\section{Real-time PCR}

After reverse-transcription to cDNA from total RNA, we performed quantification by realtime PCR (LightCycler instrument, Roche) using the LightCycler FastStart DNA Master HybProbe Kit (Roche). We normalized the results for CXCL2 relative to $\beta$-actin expression. For details, see Supplementary Methods.

\section{Isolation of bone marrow neutrophils}

We isolated mouse bone marrow neutrophils from femurs and tibias by Percoll density gradient centrifugation. We lysed the remaining erythrocytes with buffer containing (in $\mathrm{mM}$ ): 150 $\mathrm{NH}_{4} \mathrm{Cl}, 1 \mathrm{KHCO}_{3}$ and $0.1 \mathrm{Na}_{2}$ EDTA. For details, see Supplementary Methods.

\section{In vitro migration assay}

We used 6.5-mm diameter well chambers with $3-\mu \mathrm{m}$ pore size membranes (Costar) to determine neutrophil chemotaxis. We added the tested supernatants to the lower chamber. We allowed neutrophils $\left(5 \times 10^{5}\right.$ cells) isolated from bone marrow to migrate from the upper to the lower chamber for $1.5 \mathrm{~h}$ and then counted the number of migrating cells. We added CXCL2specific antibody (R\&D Systems) or isotype control antibody IgG2B (MBL) to the culture medium in the lower chamber.

\section{Induction of colitis by dextran sulfate sodium}

We gave mice sterile distilled water containing 2.5\% DSS (molecular weight 36,000-50,000) ad libitum throughout the experiment.

\section{Immunofluorescent staining of colon sections}

We placed colon specimens in Tissue-Tek optimum cutting-temperature compound (Sakura), snap-froze them in dry ice and ethanol and stored them at $-80^{\circ} \mathrm{C}$. After fixation and rehydration, we then incubated samples with R-phycoerythrin (R-PE)-conjugated mouse F4/80-specific antibody (Serotec) and FITC-conjugated mouse GR1-specific antibody (BD Pharmingen). We acquired the fluorescence images with a confocal laser-scanning microscope and counted the numbers of GR1-positive neutrophils and F4/80-positive macrophages in the images. For details, see Supplementary Methods.

\section{Myeloperoxidase assay}

After freeze-and-thaw and centrifugation of homogenized colon specimens, we mixed $100 \mathrm{ml}$ of supernatant with a solution of $0.167 \mathrm{mg} \mathrm{ml}^{-1} O$-dianisidine hydrochloride and $0.0005 \%$ $\mathrm{H}_{2} \mathrm{O}_{2}$. We measured myeloperoxidase activity spectrophotometrically as the change in absorbance at $460 \mathrm{~nm}$. For details, see Supplementary Methods.

\section{Histological evaluation of colonic lesions}

We stained colon sections fixed with formalin and embedded in paraffin with H\&E for the morphological evaluation. We graded the histopathological change on a scale from 0 to 3 according to the following criteria: 0 , no remarkable change; 1 , slight change; 2 , moderate change; and 3, marked change. We calculated the histological score of ulceration by adding each score for proximal, middle and distal colon. For details, see Supplementary Methods.

\section{Statistical analyses}

All data are expressed as means \pm s.e.m. We accumulated the data for each condition from at least three independent experiments. We evaluated statistical significance with the Student's $t$-test for comparisons between two mean values. We carried out multiple comparisons between more than three groups with an ANOVA followed by Tukey-Kramer test. 


\section{Supplementary Material}

Refer to Web version on PubMed Central for supplementary material.

\section{Acknowledgments}

We thank T. Niidome, T. Nakagawa and H. Shirakawa for their support in mouse experiments and M. Hikida, T. Yamazaki and K. Takahara for helpful advice. This study was supported by research grants from the Ministry of Education, Culture, Sports, Science, and Technology of Japan, the Japan Society for the Promotion of Science, Japan Science and Technology Agency, and the US National Institutes of Health.

\section{References}

1. Luster AD. Chemokines—chemotactic cytokines that mediate inflammation. N. Engl. J. Med 1998;338:436-445. [PubMed: 9459648]

2. Sonoda $\mathrm{Y}$, et al. Physiologic regulation of postovulatory neutrophil migration into vagina in mice by a C-X-C chemokine(s). J. Immunol 1998:6159-6165. [PubMed: 9637534]

3. Fialkow L, Wang Y, Downey GP. Reactive oxygen and nitrogen species as signaling molecules regulating neutrophil function. Free Radic. Biol. Med 2007;42:153-164. [PubMed: 17189821]

4. Henricks PAJ, Nijkamp FP. Reactive oxygen species as mediators in asthma. Pulm. Pharmacol. Ther 2001;14:409-421. [PubMed: 11782121]

5. Dröge W. Free radicals in the physiological control of cell function. Physiol. Rev 2002;82:47-95. [PubMed: 11773609]

6. Cavaillon JM, Adib-Conquy M. Monocytes/macrophages and sepsis. Crit. Care Med 2005;33:S506S509. [PubMed: 16340435]

7. Josse C, Boelaert JR, Best-Belpomme M, Piette J. Importance of post-transcriptional regulation of chemokine genes by oxidative stress. Biochem. J 2001;360:321-333. [PubMed: 11716760]

8. Zeng X, Dai J, Remick DG, Wang X. Homocysteine mediated expression and secretion of monocyte chemoattractant protein-1 and interleukin-8 in human monocytes. Circ. Res 2003;93:311-320. [PubMed: 12881478]

9. Feske S, Giltnane J, Dolmetsch R, Staudt LM, Rao A. Gene regulation mediated by calcium signals in T lymphocytes. Nat. Immunol 2001;2:316-324. [PubMed: 11276202]

10. Wilson L, Butcher CJ, Kellie S. Calcium ionophore A23187 induces interleukin-8 gene expression and protein secretion in human monocytic cells. FEBS Lett 1993;325:295-298. [PubMed: 8319811]

11. Méndez-Samperio P, Palma-Barrios J, Vázquez-Hernández A, García-Martinez E. Secretion of interleukin- 8 by human-derived cell lines infected with Mycobacterium bovis. Mediators Inflamm 2004;13:45-49. [PubMed: 15203565]

12. Clapham DE. TRP channels as cellular sensors. Nature 2003;426:517-524. [PubMed: 14654832]

13. Perraud AL, et al. ADP-ribose gating of the calcium-permeable LTRPC2 channel revealed by Nudix motif homology. Nature 2001;411:595-599. [PubMed: 11385575]

14. Hara Y, et al. LTRPC2 $\mathrm{Ca}^{2+}$-permeable channel activated by changes in redox status confers susceptibility to cell death. Mol. Cell 2002;9:163-173. [PubMed: 11804595]

15. Massullo P, Sumoza-Toledo A, Bhagat H, Partida-Sánchez S. TRPM channels, calcium and redox sensors during innate immune responses. Semin. Cell Dev. Biol 2006;17:654-666. [PubMed: 17178241]

16. Perraud AL, et al. Accumulation of free ADP-ribose from mitochondria mediates oxidative stressinduced gating of TRPM2 cation channels. J. Biol. Chem 2005;280:6138-6148. [PubMed: 15561722]

17. Kaneko S, et al. A critical role of TRPM2 in neuronal cell death by hydrogen peroxide. J. Pharmacol. Sci 2006;101:66-76. [PubMed: 16651700]

18. Korenaga $D$, et al. Impaired antioxidant defense system of colonic tissue and cancer development in dextran sulfate sodium-induced colitis in mice. J. Surg. Res 2002;102:144-149. [PubMed: 11796011] 
19. Blackburn AC, Doe WF, Buffinton GD. Salicylate hydroxylation as an indicator of hydroxyl radical generation in dextran sulfate-induced colitis. Free Radic. Biol. Med 1998;25:305-313. [PubMed: 9680176]

20. Araki Y, Sugihara H, Hattori T. The free radical scavengers edaravone and tempol suppress experimental dextran sulfate sodium-induced colitis in mice. Int. J. Mol. Med 2006;17:331-334. [PubMed: 16391834]

21. Chiu LL, Perng DW, Yu CH, Su SN, Chow LP. Mold allergen, pen C 13, induces IL-8 expression in human airway epithelial cells by activating protease-activated receptor 1 and 2. J. Immunol 2007;178:5237-5244. [PubMed: 17404307]

22. Mizukami Y, et al. Induction of interleukin- 8 preserves the angiogenic response in HIF-1 $\alpha$-deficient colon cancer cells. Nat. Med 2005;11:992-997. [PubMed: 16127434]

23. Yoshida T, et al. Nitric oxide activates TRP channels by cysteine S-nitrosylation. Nat. Chem. Biol 2006;2:596-607. [PubMed: 16998480]

24. Dejardin E, et al. The lymphotoxin- $\beta$ receptor induces different patterns of gene expression via two NF- $\kappa$ B pathways. Immunity 2002;17:525-535. [PubMed: 12387745]

25. Lev S, et al. Protein tyrosine kinase PYK2 involved in $\mathrm{Ca}^{2+}$-induced regulation of ion channel and MAP kinase functions. Nature 1995;376:737-745. [PubMed: 7544443]

26. Roose JP, Mollenauer M, Gupta VA, Stone J, Weiss A. A diacylglycerol-protein kinase C-RasGRP1 pathway directs Ras activation upon antigen receptor stimulation of Tcells. Mol. Cell. Biol 2005;25:4426-4441. [PubMed: 15899849]

27. Jaramillo M, Olivier M. Hydrogen peroxide induces murine macrophage chemokine gene transcription via extracellular signal-regulated kinase- and cyclic adenosine 5'-monophosphate (cAMP)-dependent pathways: involvement of NF- $\mathrm{kB}$, activator protein 1, and cAMP response element binding protein. J. Immunol 2002;169:7026-7038. [PubMed: 12471138]

28. Gloire G, Legrand-Poels S, Piette J. NF- $\kappa$ B activation by reactive oxygen species: fifteen years later. Biochem. Pharmacol 2006;72:1493-1505. [PubMed: 16723122]

29. Kim D-S, Han JH, Kwon HJ. NF- $\kappa$ B and c-Jun-dependent regulation of macrophage inflammatory protein-2 gene expression in response to lipopolysaccharide in RAW 264.7 cells. Mol. Immunol 2003;40:633-643. [PubMed: 14597166]

30. Ohtsuka Y, Sanderson IR. Dextran sulfate sodium-induced inflammation is enhanced by intestinal epithelial cell chemokine expression in mice. Pediatr. Res 2003;53:143-147. [PubMed: 12508094]

31. Saklatvala J. The p38 MAP kinase pathway as a therapeutic target in inflammatory disease. Curr. Opin. Pharmacol 2004;4:372-377. [PubMed: 15251131]

32. Lee K, Esselman WJ. cAMP potentiates $\mathrm{H}_{2} \mathrm{O}_{2}$-induced ERK1/2 phosphorylation without the requirement for MEK1/2 phosphorylation. Cell. Signal 2001;13:645-652. [PubMed: 11495722]

33. Seimiya H, Tsuruo T. Differential expression of protein tyrosine phosphatase genes during phorbol ester-induced differentiation of human leukemia U937 cells. Cell Growth Differ 1993;4:1033-1039. [PubMed: 8117617]

34. Zhang W, et al. Regulation of TRP channel TRPM2 by the tyrosine phosphatase PTPL1. Am. J. Physiol. Cell Physiol 2007;292:C1746-C1758. [PubMed: 17251321]

35. Lambeth JD. NOX enzymes and the biology of reactive oxygen. Nat. Rev. Immunol 2004;4:181189. [PubMed: 15039755]

36. Khor TO, et al. Nrf2-deficient mice have an increased susceptibility to dextran sulfate sodiuminduced colitis. Cancer Res 2006;66:11580-11584. [PubMed: 17178849]

37. Han XB, Liu X, Hsueh W, De Plaen IG. Macrophage inflammatory protein-2 mediates the bowel injury induced by platelet-activating factor. Am. J. Physiol. Gastrointest. Liver Physiol 2004;287:G1220-G1226. [PubMed: 15319184]

38. Buanne $\mathrm{P}$, et al. Crucial pathophysiological role of CXCR2 in experimental ulcerative colitis in mice. J. Leukoc. Biol 2007;82:1239-1246. [PubMed: 17656654]

39. Keshavarzian A, et al. Increased interleukin-8 (IL-8) in rectal dialysate from patients with ulcerative colitis: evidence for a biological role for IL-8 in inflammation of the colon. Am. J. Gastroenterol 1999;94:704-712. [PubMed: 10086655] 
40. Anezaki K, et al. Correlations between interleukin-8, and myeloperoxidase or luminol-dependent chemiluminescence in inflamed mucosa of ulcerative colitis. Intern. Med 1998;37:253-258. [PubMed: 9617859]

41. Grip O, Janciauskiene S, Lindgren S. Macrophages in inflammatory bowel disease. Curr. Drug Targets Inflamm. Allergy 2003;2:155-160. [PubMed: 14561168]

42. Smith PD, Ochsenbauer-Jambor C, Smythies LE. Intestinal macrophages: unique effector cells of the innate immune system. Immunol. Rev. 2005;206:149-159.

43. Mahida YR. The key role of macrophages in the immunopathogenesis of inflammatory bowel disease. Inflamm. Bowel Dis 2000;6:21-33. [PubMed: 10701146]

44. Videla LA, Fernández V, Tapia G, Varela P. Oxidative stress-mediated hepatotoxicity of iron and copper: role of Kupffer cells. Biometals 2003;16:103-111. [PubMed: 12572670]

45. Barnes PJ. COPD: is there light at the end of the tunnel? Curr. Opin. Pharmacol 2004;4:263-272. [PubMed: 15140418]

46. Hermosura MC, Garruto RM. TRPM7 and TRPM2 — candidate susceptibility genes for Western Pacific ALS and PD? Biochim. Biophys. Acta 2007;1772:822-835. [PubMed: 17395433]

47. Fonfria E, et al. TRPM2 channel opening in response to oxidative stress is dependent on activation of poly(ADP-ribose) polymerase. Br. J. Pharmacol 2004;143:186-192. [PubMed: 15302683]

48. Cuzzocrea S, et al. Role of poly(ADP-ribose) glycohydrolase in the development of inflammatory bowel disease in mice. Free Radic. Biol. Med 2007;42:90-105. [PubMed: 17157196]

49. Haskó G, et al. Poly(ADP-ribose) polymerase is a regulator of chemokine production: relevance for the pathogenesis of shock and inflammation. Mol. Med 2002;8:283-289. [PubMed: 12359959]

50. Partida-Sánchez S, et al. Cyclic ADP-ribose production by CD38 regulates intra-cellular calcium release, extracellular calcium influx and chemotaxis in neutrophils and is required for bacterial clearance in vivo. Nat. Med 2001;7:1209-1216. [PubMed: 11689885] 

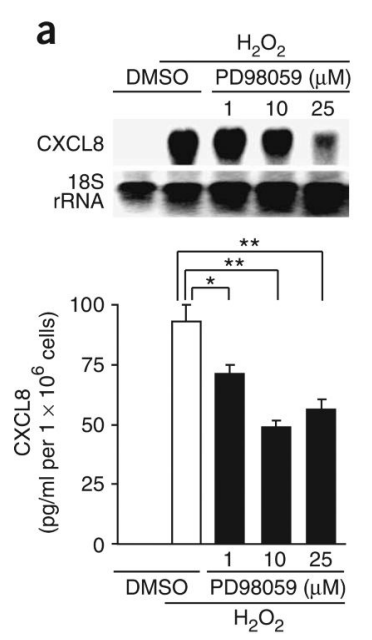

b

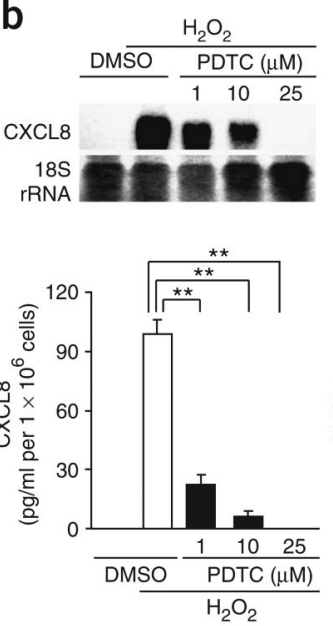

C

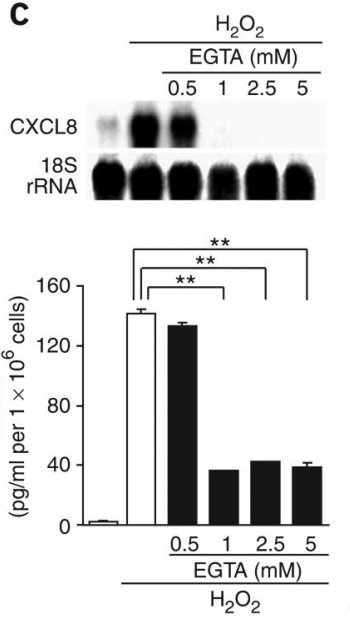

d

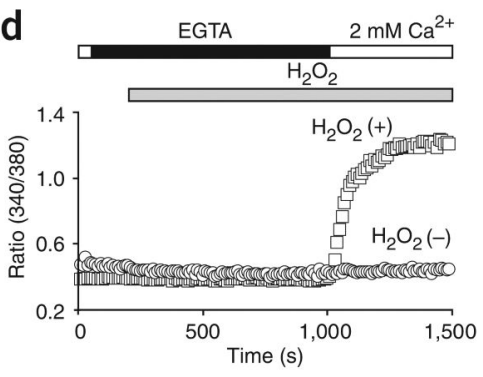

e
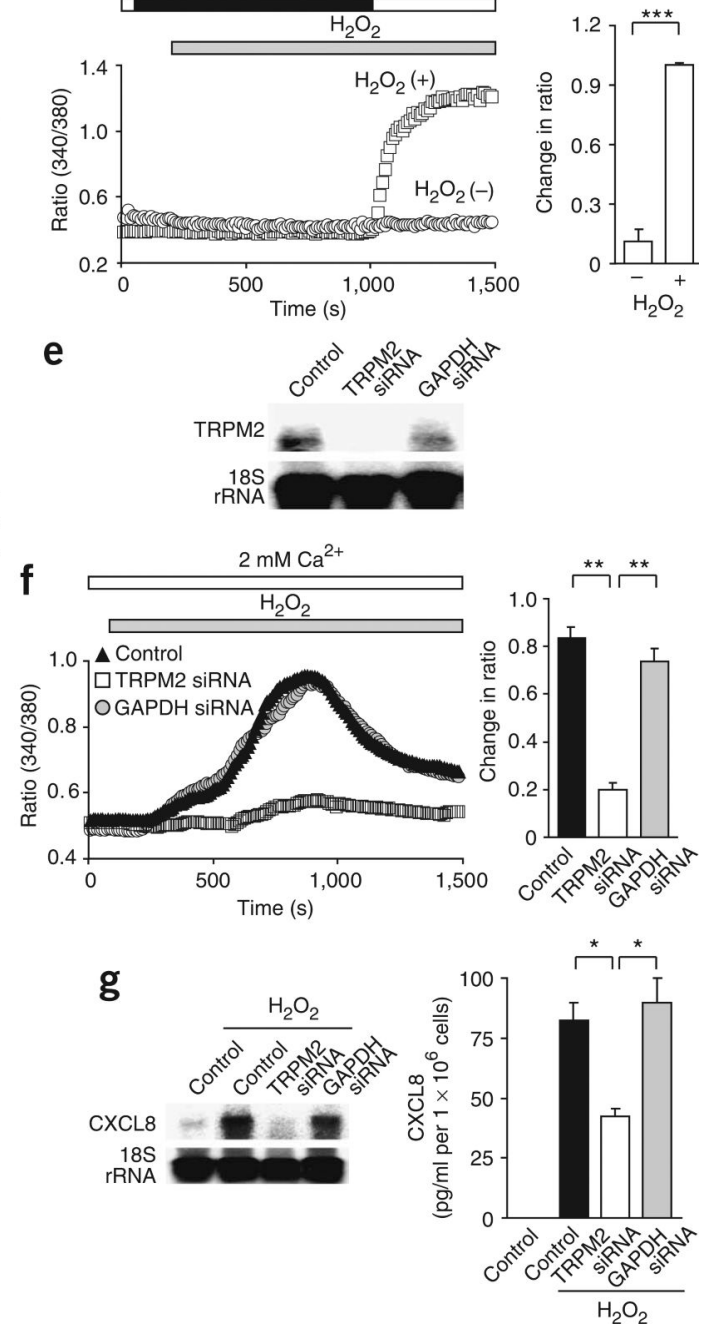

Figure 1.

Erk-, NF- $\mathrm{kB}$ - and TRPM2-mediated $\mathrm{Ca}^{2+}$ entry control $\mathrm{H}_{2} \mathrm{O}_{2}$-induced CXCL8 expression in U937 cells. (a,b) Inhibitory effects of PD98059 (a) and PDTC (b) on $\mathrm{H}_{2} \mathrm{O}_{2}(250 \mu \mathrm{M})$-induced expression of CXCL8 mRNA (top, northern blot) and protein secretion (bottom, ELISA). (c) Inhibitory effect of removal of extracellular $\mathrm{Ca}^{2+}$ by EGTA on $\mathrm{H}_{2} \mathrm{O}_{2}(250 \mu \mathrm{M})$-induced expression of CXCL8 mRNA (top) and secretion (bottom). (d) Averaged time courses of $\left[\mathrm{Ca}^{2+}\right]_{\mathrm{i}}$ changes indicated by the ratio of two fluorescence intensities (340/380) (left) and maximum $\left[\mathrm{Ca}^{2+}\right]_{\mathrm{i}}$ elevations (right) owing to $\mathrm{H}_{2} \mathrm{O}_{2}(250 \mu \mathrm{M})$-induced $\mathrm{Ca}^{2+}$ influx $(n=72-$ 75). After 13 min of exposure to $250 \mu \mathrm{M} \mathrm{H}_{2} \mathrm{O}_{2}$ in $\mathrm{Ca}^{2+}{ }_{\text {-free }} 0.5 \mathrm{mMEGTA}$-containing solution, cells were exposed to $250 \mu \mathrm{M} \mathrm{H}_{2} \mathrm{O}_{2}$ and then later to $2 \mathrm{mM} \mathrm{Ca}^{2+}$ to evoke a Ca${ }^{2+}$ response due to $\mathrm{H}_{2} \mathrm{O}_{2}$-induced $\mathrm{Ca}^{2+}$ influx. (e-g) Effects of siRNA specific for TRPM2. (e) TRPM2 mRNA expression in cells transfected with siRNA specific for TRPM2 or GAPDH. (f) Averaged time courses of $\mathrm{H}_{2} \mathrm{O}_{2}(250 \mu \mathrm{M})$-evoked $\left[\mathrm{Ca}^{2+}\right]_{\mathrm{i}}$ changes (left) and maximum $\left[\mathrm{Ca}^{2+}\right]_{\mathrm{i}}$ elevations (right) in cells transfected with siRNA specific for TRPM2 or GAPDH or in control cells $(n=162-176)$. (g) Expression of CXCL8 mRNA (left) and secretion (right) induced by treatment with $250 \mu \mathrm{M} \mathrm{H}_{2} \mathrm{O}_{2}$ for $6 \mathrm{~h}$ and $12 \mathrm{~h}$, respectively, in cells transfected with siRNA for TRPM2 or GAPDH or in control cells. Data points are means \pm s.e.m. $* P<$ $0.05, * * P<0.01$ and $* * * P<0.001$. 
a

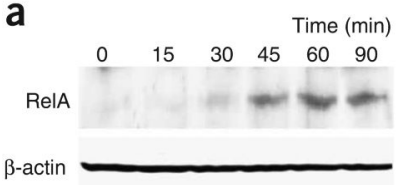

C
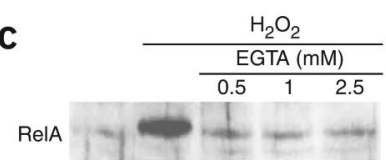

$\beta$-actin

e

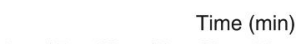

$\begin{array}{llllll}0 & 15 & 30 & 45 & 60 & 90\end{array}$ plкB

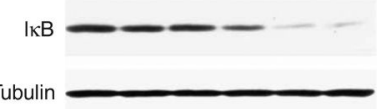

g

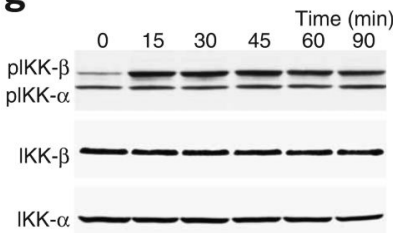

b

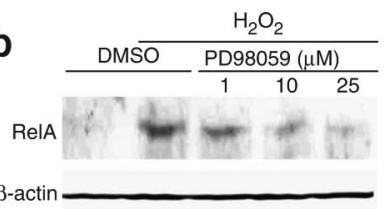

d

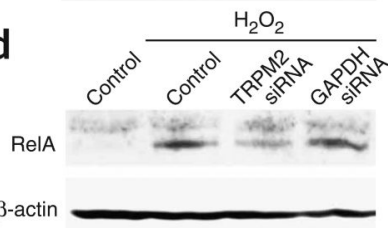

f

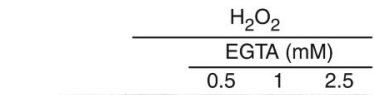

$\mathrm{p} \mid \mathrm{kB}$
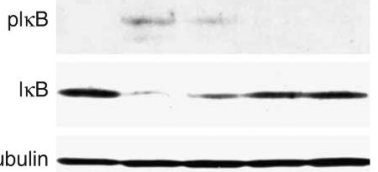

h
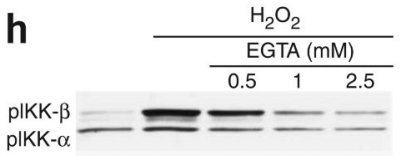

$\mathrm{IKK}-\beta \longrightarrow$

IKK- $\alpha-\longrightarrow$

Figure 2.

TRPM2-mediated $\mathrm{Ca}^{2+}$ influx controls $\mathrm{H}_{2} \mathrm{O}_{2}$-induced nuclear translocation of NF- $\kappa \mathrm{B}$ via Erk in U937 cells. (a) Nuclear translocation of NF- $\kappa \mathrm{B}$ RelA induced by incubation with $250 \mu \mathrm{M}$ $\mathrm{H}_{2} \mathrm{O}_{2}$ as assessed at the indicated time points by western blotting. (b,c) Effects of PD98059 (b) and removal of extracellular $\mathrm{Ca}^{2+}$ by EGTA (c) on nuclear translocation of NF- $\mathrm{KB}$ after of 60 min $\mathrm{H}_{2} \mathrm{O}_{2}(250 \mu \mathrm{M})$ incubation. (d) Suppression of nuclear translocation of NF- $\mathrm{KB}$ by siRNA specific for TRPM2 after $60 \mathrm{~min} \mathrm{H}_{2} \mathrm{O}_{2}(250 \mu \mathrm{M})$ incubation. (e) Time courses of phosphorylation and degradation of I $\kappa \mathrm{B}$ induced by incubation with $250 \mu \mathrm{M} \mathrm{H}_{2} \mathrm{O}_{2}$. pI $\mathrm{B}$, phosphorylated I $\mathrm{KB}$. (f) Effects of removal of extracellular $\mathrm{Ca}^{2+}$ by EGTA on phosphorylation and degradation of $\mathrm{I} \kappa \mathrm{B}$ induced by $250 \mu \mathrm{M} \mathrm{H}_{2} \mathrm{O}_{2}(60 \mathrm{~min})$. (g) Time courses of phosphorylation of IKK- $\beta$ and IKK- $\alpha$ (pIKK- $\beta$ and pIKK- $\alpha$ ) induced by incubation with $250 \mu \mathrm{M} \mathrm{H}_{2} \mathrm{O}_{2}$. (h) Effects of removal of extracellular $\mathrm{Ca}^{2+}$ by EGTA on phosphorylation of IKK- $\beta$ and IKK- $\alpha$ induced by $250 \mu \mathrm{M} \mathrm{H}_{2} \mathrm{O}_{2}(60 \mathrm{~min})$. 

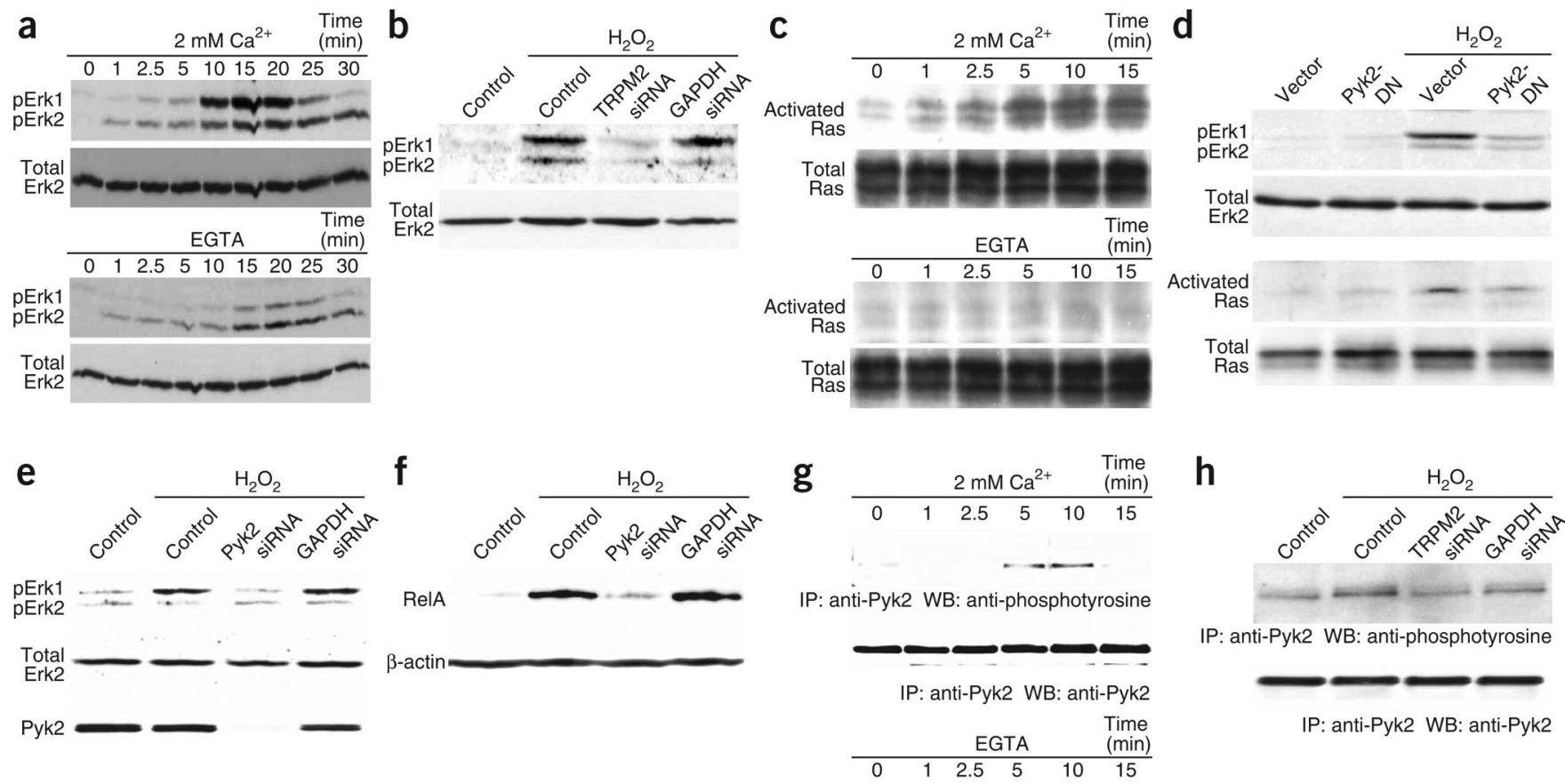

IP: anti-Pyk2 WB: anti-phosphotyrosine

IP: anti-Pyk2 WB: anti-Pyk2

Figure 3.

TRPM2-mediated $\mathrm{Ca}^{2+}$ influx activates Pyk2 and Ras to amplify Erk signal in U937 cells. (a) Erk activation induced by $250 \mu \mathrm{M} \mathrm{H}_{2} \mathrm{O}_{2}$ at the indicated time points of treatment in the presence (top) or absence (bottom) of extracellular $\mathrm{Ca}^{2+}$. Activated Erk (pErk1 and pErk2: phosphorylated Erk1/2) is detected by phospho-Erk1/2-specific antibody. (b) Suppression of Erk activation by siRNA specific for TRPM2 after 10 min of $\mathrm{H}_{2} \mathrm{O}_{2}(250 \mu \mathrm{M})$ treatment. (c) Ras activation induced by $250 \mu \mathrm{M} \mathrm{H}_{2} \mathrm{O}_{2}$ at the indicated time points of treatment in the presence (top) or absence (bottom) of extracellular $\mathrm{Ca}^{2+}$. (d) Inhibitory effects of Pyk2-DN on Erk (top) and Ras (bottom) activation after 10 min of $\mathrm{H}_{2} \mathrm{O}_{2}(250 \mu \mathrm{M})$ treatment. (e) Suppressive effects of Pyk2-specific siRNAs on Erk activation after $10 \mathrm{~min}$ of $\mathrm{H}_{2} \mathrm{O}_{2}(250 \mu \mathrm{M})$ treatment. (f) Suppressive effects of Pyk2-specific siRNAs on nuclear translocation of NF-kB RelA after 60 min of $\mathrm{H}_{2} \mathrm{O}_{2}\left(250 \mu \mathrm{M}\right.$ ) incubation. (g) Pyk2 activation induced by $250 \mu \mathrm{M} \mathrm{H}_{2} \mathrm{O}_{2}$ at the indicated time points of treatment in the presence (top) or absence (lower panel) of extracellular $\mathrm{Ca}^{2+}$. IP, immunoprecipitation; WB, western blotting; anti-Pyk2, antibody to Pyk2; antiphosphotyrosine, antibody to phosphorylated tyrosine. (h) Suppressive effects of TRPM2specific siRNA on Pyk2 activation after 10 min of $\mathrm{H}_{2} \mathrm{O}_{2}(250 \mu \mathrm{M})$ treatment. 


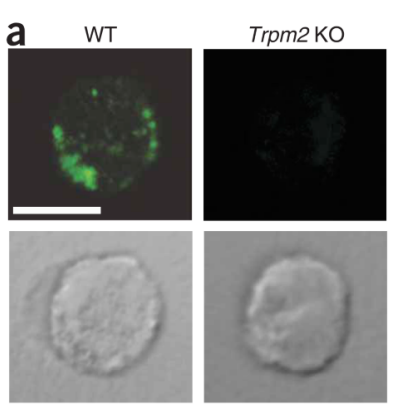

e

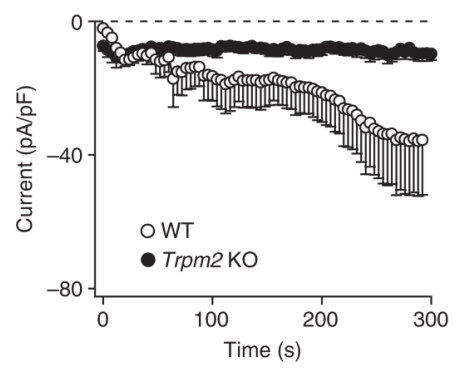

b

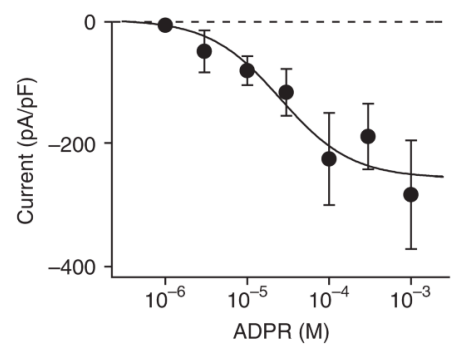

f

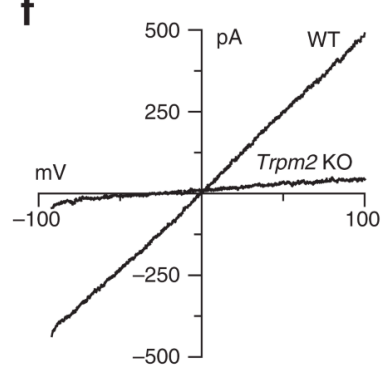

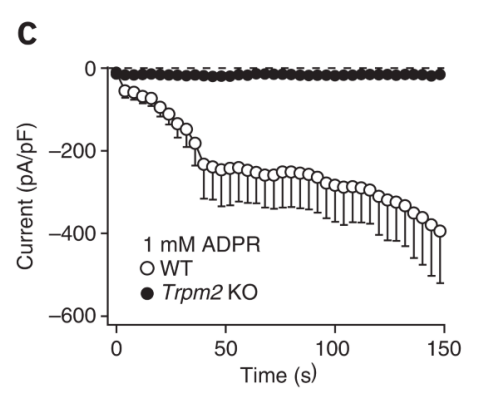

g

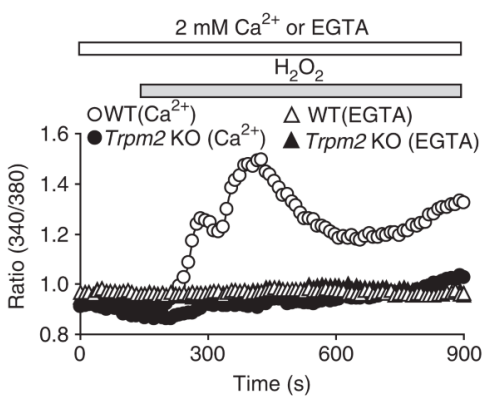

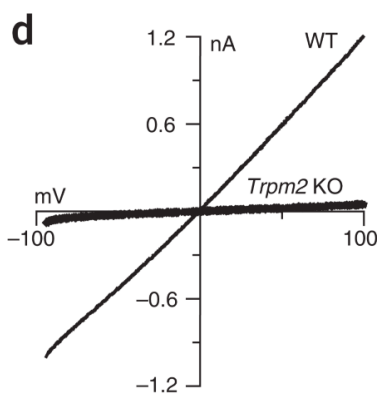

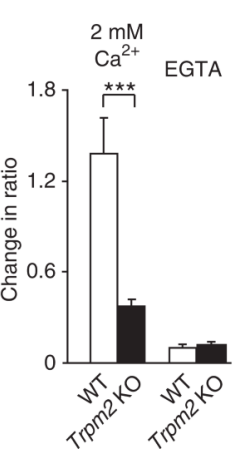

Figure 4.

TRPM2 currents activated by ADPR and $\mathrm{H}_{2} \mathrm{O}_{2}$ are disrupted in Trpm2-knockout monocytes.

(a) Confocal images of immunostaining with TRPM2-specific antibody (top) and differential interference contrast images (bottom) of Trpm2-knockout (KO) monocytes. Scale bar, $5 \mu \mathrm{m}$. (b) Dose-response curve of currents induced by internal perfusion with ADPR in WT monocytes. Current amplitudes are measured at $-80 \mathrm{mV}$ and $100 \mathrm{~s}$, normalized for cell size, averaged and plotted against the respective ADPR concentrations $(n=5-7)$. A fit to the data points calculates the $K_{\mathrm{d}}$ at $25 \mu \mathrm{M}$ with a Hill coefficient of 1 . (c) Time course of current development induced at $-80 \mathrm{mV}$ by intracellular perfusion of WT $(n=6)$ or Trpm2-KO monocytes $(n=11)$ with $1 \mathrm{mM}$ ADPR. (d) Representative current-voltage relationship obtained by a 50 -ms voltage ramp pulse $\left(-100 \mathrm{mV}\right.$ to $\left.+{ }^{`} 00 \mathrm{mV}\right)$ from WT or Trpm2--KO monocytes after $100 \mathrm{~s}$ of ADPR perfusion. (e) Averaged current development induced at $-80 \mathrm{mV}$ by intrapipette $\mathrm{H}_{2} \mathrm{O}_{2}(100 \mu \mathrm{M})$ in WT $(n=8)$ or Trpm2-KO monocytes $(n=11)$. (f) Representative current-voltage relationship in WT or Trpm2-KO monocytes after $300 \mathrm{~s}$ of $\mathrm{H}_{2} \mathrm{O}_{2}$ perfusion. (g) Averaged time courses of $\left[\mathrm{Ca}^{2+}\right]_{\mathrm{i}}$ changes (left) and maximum $\left[\mathrm{Ca}^{2+}\right]_{\mathrm{i}}$ elevation (right) induced by $25 \mu \mathrm{M} \mathrm{H}_{2} \mathrm{O}_{2}$ in WT $(n=24)$ or Trpm2-KO $(n=59)$ monocytes in $\mathrm{Ca}^{2+}$-containing or $\mathrm{Ca}^{2+}$-free $0.5 \mathrm{mM}$ EGTA-containing solution. Data points are means \pm s.e.m. $* * * P<0.001$. 
a

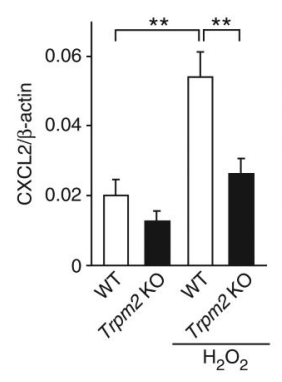

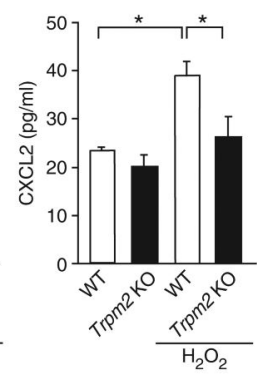

b

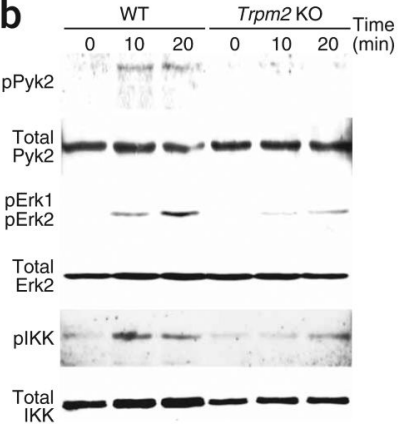

C

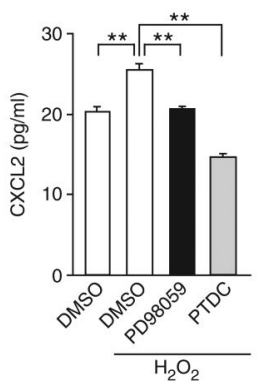

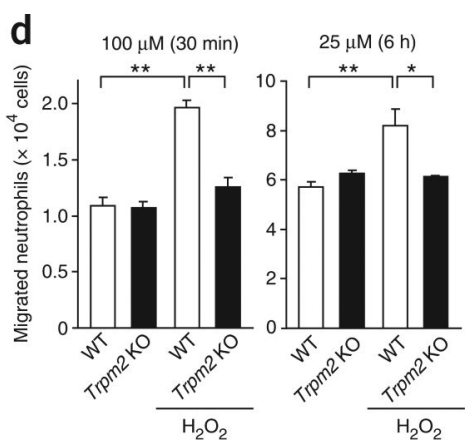

e

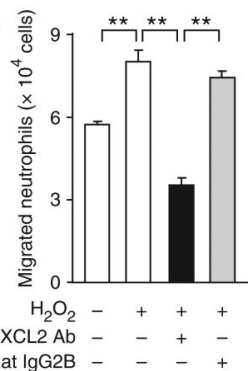

Figure 5.

$\mathrm{H}_{2} \mathrm{O}_{2}$-induced CXCL2 production and the underlying signal transduction are impaired in Trpm2 KO monocytes. (a) Expression levels of CXCL2 mRNA (left, real-time PCR) and CXCL2 protein secretion (right, ELISA) in monocytes isolated from WT or Trpm2-KO mice after treatment with $25 \mu \mathrm{M} \mathrm{H}_{2} \mathrm{O}_{2}$ for $3 \mathrm{~h}$ and $6 \mathrm{~h}$, respectively. (b) Pyk2, Erk and NF- $\mathrm{KB}$ pathway activation induced by $25 \mu \mathrm{M} \mathrm{H}_{2} \mathrm{O}_{2}$ at the indicated time points of treatment in monocytes isolated from peripheral blood of WT and Trpm2-KO mice. (c) Inhibitory effects of Erk pathway inhibitor PD98059 and NF- $\mathrm{BB}$ inhibitor PDTC on $\mathrm{H}_{2} \mathrm{O}_{2}(25 \mu \mathrm{M})$-induced expression of CXCL2 protein. (d) In vitro migration of neutrophils from WT mice by chemokines released from $\mathrm{H}_{2} \mathrm{O}_{2}$-treated monocytes isolated from WT or Trpm2-KO mice. Monocytes were cultured in the presence or absence of $100 \mu \mathrm{M} \mathrm{H}_{2} \mathrm{O}_{2}$ for $30 \mathrm{~min}$ (left) or 25 $\mu \mathrm{M} \mathrm{H}_{2} \mathrm{O}_{2}$ for $6 \mathrm{~h}$ (right). After centrifugation of the cell suspension, the cells were resuspended in medium without $\mathrm{H}_{2} \mathrm{O}_{2}$ and incubated for $12 \mathrm{~h}$ (left) or $6 \mathrm{~h}$ (right). After removal of the cells by centrifugation, the supernatant derived from the culture medium was used in a neutrophil chemotaxis assay. (e) Inhibitory effects of neutralizing monoclonal antibody to CXCL2 on neutrophil chemotaxis induced by chemokines released from $25 \mu \mathrm{M} \mathrm{H}_{2} \mathrm{O}_{2}$-treated WT monocytes. Antibody to CXCL2 or isotype control (IgG2B) was added to the culture medium. Data points are means \pm s.e.m. $* P<0.05$ and $* * P<0.01$. 
a

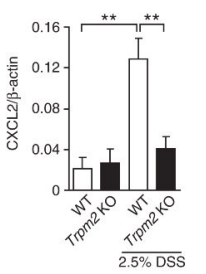

C

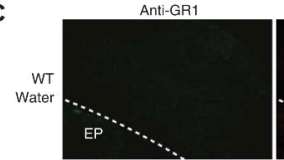

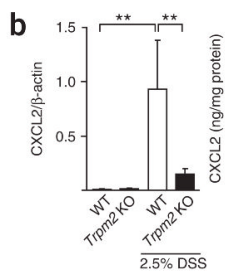

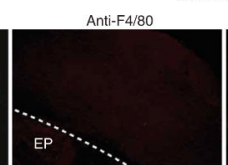

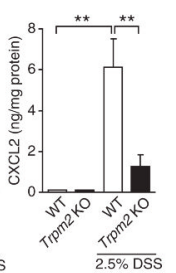
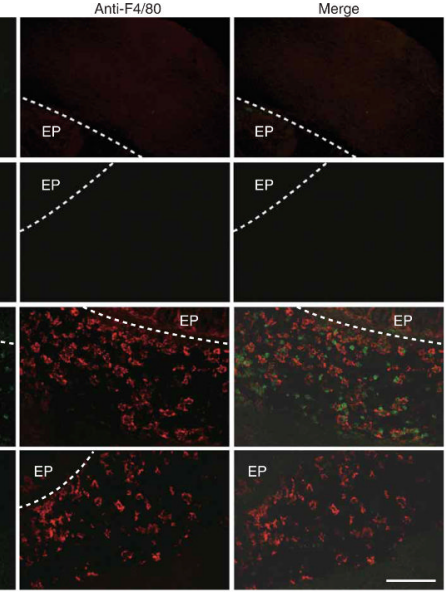

d

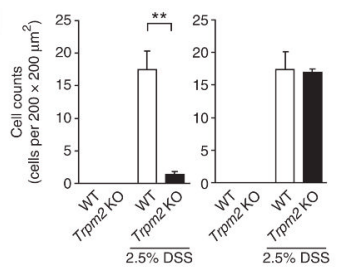

WT
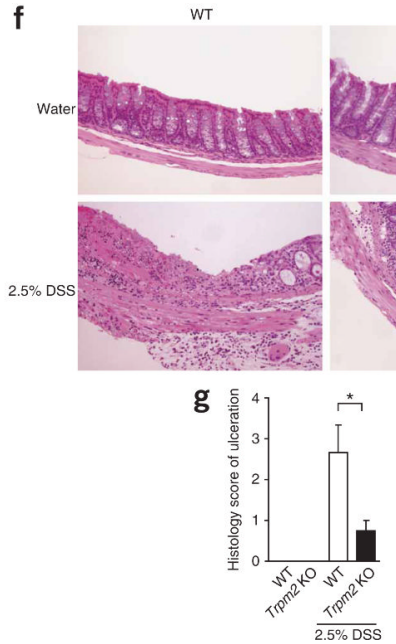

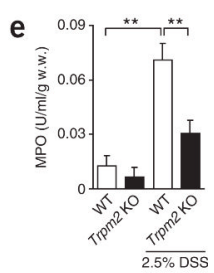

Trpm2 KO

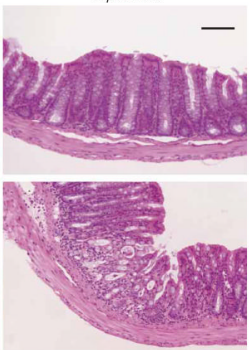

,

Figure 6.

Trpm2 deficiency suppresses exacerbation of inflammation in colitis mouse model. (a,b) Suppression of DSS-induced CXCL2 expression in Trpm2-KO mice. (a) CXCL2 expression levels of mRNA in monocytes isolated from peripheral blood. (b) Expression levels of CXCL2 mRNA (left) and protein (right) in the colon. (c) Dual immunofluorescent staining of colon tissue is performed with FITC-conjugated mouse GR1-specific antibody (anti-GR1, green) and R-PE-conjugated mouse F4/80-specific antibody (anti-F4/80, red). Submucosal and muscular layer and epithelium (EP) are shown. Water-treated WT, water-treated Trpm2-KO, DSStreated WT and DSS-treated Trpm2-KO colons were used. Scale bar, $100 \mu \mathrm{m}$. (d) Cell counts of GR1-positive neutrophils (left) and F4/80-positive macrophages (right) in the colons of control and DSS-treated WT or Trpm2-KO mice (cells per $200 \times 200 \mu^{2}$ ). (e) Activity of myeloperoxidase (MPO) in the colons of WT and Trpm2-KO mice. Data are normalized to colon wet weight (g w.w.). (f) H\&E staining of colons isolated from water- or DSS-treated mice are shown, representing morphological findings for colons with histological score of ulceration. The histological scores of ulceration in the water-treated WT, water-treated Trpm2-KO, DSS-treated WT and DSS-treated Trpm2 KO colons shown are 0, 0, 3 and 0, respectively. Scale bar, $1 \mathrm{~mm}$. (g) Histology scores with respect to ulceration on a scale of $0-$ 3 of WT or Trpm2-KO mice. Data points are mean \pm s.e.m. ${ }^{*} P<0.05$ and $* * P<0.01$. 